\title{
SOBRE UN FÉMUR CON GRABADOS PERTENECIENTE A LA CULTURA MEXICA
}

Nelly GutTírRez Solana

Los grabados del fémur analizados en este artículo representan creen. cias fundamentales dentro de la cultura mexica expresadas a través de una iconografía que, además de ser característica del Posclásico Tardio, muestra detalles atribuibles a dicha cultura. Esta pieza, asimismo, corrobora lo narrado en las fuentes escritas en los primeros siglos posteriores a la conquista acerca de los mitos y costumbres de la última gran cultura mesoamericana.

En el boletín 31 del INAH, los arqueólogos Cepeda y Arana informan sobre el descubrimiento de un fémur durante las excavaciones del Metro en la ciudad de México. Los autores indican que se trata de un omichicahuaztli o raspador musical, en el que se grabó una escena lo suficientemente importante como para ameritar un análisis detallado, el cual me propongo llevar a cabo en este artículo (lámina 1). Otro hueso, hallado en Culhuacán y descrito detenidamente por Hasso von Winning, presenta paralelismos interesantes con el aquí estudiado, por lo cual me referiré a él frecuentemente (lámina 2).

Cepeda y Arana describen el hueso como un fémur humano incompleto, de $17 \mathrm{~cm}$. de largo, con seis muescas hechas posteriormente que el diseño inciso. ${ }^{1}$ Fue localizado "en la calle de Izazaga a 1.20 metros al este de la esquina sudeste de la que forman la calle citada y Bolívar"," y a 2.25 metros de profundidad en una capa con restos prehispánicos. La presencia de las muescas es lo que permitió clasificarlo como un omichicahuaztli. El uso de este instrumento musical es mencionado en las fuentes cuando se describen los ritos acompañantes de las exequias de los ilatoque y guerreros importantes. Así, Alvarado Tezozómoc narra: "los mozos tocando el omichicahuaztli de hueso de venado, hueco y aserrado, en todos los actos del canto y el baile, le arrancaban una resonancia muy triste, semejando la de un caracol". ${ }^{3}$ El hueso podría ser de animal -como lo determina la cita anterior- o humano, como en el caso tanto del fémur del Metro, como del hallado

\footnotetext{
1 Cepeda y Arana, 1969, p. 38

2 Ibid.

3 Alvarado Tezozómoc, 1943, p. 18.
} 
en Culhuacán. Según Beyer, el raspador "se tomaba con la mano izquierda, mientras con la otra se frotaba con una concha o un homóplato"; 4 su uso continúa en algunas tribus de México como la de los huicholes y tarahumaras, así como también en algunos pueblos del sur de Estados Unidos, como los hopis. ${ }^{5}$

Las muescas del fémur del Metro no muestran desgaste, por lo tanto, no se llegó a emplear como instrumento musical, aunque parece haber sido destinado para tal fin.

La escena principal del objeto, motivo de este estudio, está dividida en dos por una franja horizontal ancha con dos más angostas en la parte superior; en la franja ancha se grabaron dos variantes del signo conocido como el ojo radiante. En la parte superior de la escena hay un disco solar alrededor de una deidad; en la parte inferior se representó una fecha dentro de un cuadrete y dos personajes de los cuales se conservan únicamente partes de sus cabezas. Además de esta escena principal, quedan vestigios de otros elementos a la izquierda del disco solar y también en la parte superior derecha donde aparece un rostro con pintura facial y tocado con dos cuchillos.

Debido a que no contamos con muchas representaciones del dios solar en la escultura mexica, la imagen del omichicahuaztli del Metro resulta de particular interés. Las efigies en bulto de Tonatiuh del Museo de Basilea en Suiza son de las pocas que se conservan, y de una de ellas hay cierta duda sobre su identificación pues no lleva todos los rasgos característicos de dicho numen. Es indudable, en cambio, que la otra pieza es una imagen de Tonatiuh, ya que lleva el disco solar en su espalda, además de chalchihuites en la banda del tocado, elementos comunes en las efigies del mismo. La ausencia de esculturas en redondo de esta deidad parece indicar la preferencia por su representación simbólica, pues el disco solar se labró frecuentemente en objetos ceremoniales como son los llamados quauhxicallis o recipientes sagrados, las piedras de sacrificios y piedras cilíndricas y cuadrangulares de usos diversos. Obras de importancia primordial como la Piedra del Sol, la Piedra de Tízoc y el Teocalli de la Guerra Sagrada tienen esculpidos discos solares, lo que demuestra la asociación intima entre dichos monolitos y el culto al Sol.

Tonatiuh, con el disco solar, aparece dibujado en los códices del

4. Beyer, 1969, p. 536

5 Ibid. 
Grupo Borgia. En éstos puede observarse claramente la importancia del sacrificio humano para alimentar a los dioses, entre ellos el solar; por lo tanto, aunque los mexicas incrementaron la práctica de inmolar cautivos con fines rituales, éste fue un rasgo cultural heredado de pueblos más antiguos. En dichos códices, la relación entre los dioses y los hombres se limita frecuentemente a que los primeros se alimentan de los segundos, y así vemos, una y otra vez, escenas de sacrificios y autosacrificios. De maneras diversas se representan en los códices estas escenas: en algunas láminas los dioses sacan largas tiras de los cuerpos humanos, probablemente los cordones umbilicales, es decir, las deidades obtienen la esencia de la vida de aquéllos, ${ }^{6}$ mientras en otras ilustraciones, los dioses punzan, con huesos, los ojos de los hombres, lo que parece indicar la acción del autosacrificio. ${ }^{7}$ Se expresa esta relación aún con mayor claridad cuando los númenes absorben la sangxe producto de los autosacrificios. ${ }^{8}$

Además de las imágenes de Tonatiuh dibujadas en los códices, contamos con otras labradas en relieve, entre ellas la del disco de piedra de $45 \mathrm{~cm}$ de diámetro del Museum of the American Indian de Nueva York (lámina 3), al cual me referiré posteriormente, y los dos omichicahuaztlis de los cuales ya hablé.

Tonatiuh, como todos los dioses prehispánicos, puede identificarse por su atavio y atributos, aunque, como es bien sabido, hay ciertas variantes en los detalles, además de intercambios de elementos entre las diferentes deidades. El Tonatiuh del fémur del Metro puede identificarse como tal principalmente por el disco solar que lo acompaña, pero además por el tocado que presenta. Dicho tocado consiste de una hilera de chalchihuites, otra de plumas cortas además de un penacho de plumas más largas. Este tipo de tocado no corresponde al llevado por los númenes solares de los códices del Grupo Borgia, sino que es más propio de la iconografía del periodo de dominio mexica. A pesar de lo incompleto de la imagen solar del hueso de Culhúacán, puede observarse en su tocado el coronamiento de plumas cortas y largas. Tocados semejantes se pintaron en el Códice Borbónico y, en el famoso disco que lleva el nombre de Humboldt (Iámina 4), el dios ostenta un tocado casi idéntico al del fémur del Metro, inclusive la

\footnotetext{
6 Códice Borgia, 15.

7 Ibid.

8 Ibid., p. 41
} 
pluma corta al frente del penacho que se curva en dirección contraria a las demás. En la parte frontal del tocado de Tonatiuh del disco de Humboldt, se dispuso la cabeza de una mariposa, misma que aparece en los tocados de los dioses solares en los códices del Grupo Borgia; la destrucción parcial de los tocados de las imágenes del Sol en los dos omichicahuaztlis impide saber si contaban asimismo con dichos rasgos. En los dibujos del Códice Borbónico se omite dicha cabeza y, en su lugar, se dibujan ganchos o adornos de chalchihuites.

En el omichicahuaztli del Metro, es posible que Tonatiuh lleve la franja alrededor del ojo y la nariguera en forma de barra horizontal que son propias de él, pero no es posible asegurarlo. En cuanto al hueso de Culhuacán, el pectoral redondo con el signo de oro colocado al centro del disco es típico del dios solar.

Como ejemplo de un Tonatiuh con sus rasgos más característicos tenemos el figurado en el relieve conservado en el Museo de Historia Natural de Lyon, Francia.9 Dichos rasgos son: el tocado con chalchihuites, la hilera de plumas y penacho de plumas largas, la banda alrededor del ojo, la narigueta tubular y el pectoral circular áureo. La curiosa posición adoptada, en este caso, por la deidad, con un pie al aire y otro que apenas toca al suelo con las puntas de los dedos, por lo que da la impresión de correr, se repite en el disco del Museum of the American Indian. La postura de una pierna flexionada al frente y otra hacia atrás es poco común en el Códice Borgia pero, en cambio, es usual en el Códice Borbónico.

El Tonatiuh del fémur del Metro tiene el cuerpo en posición frontal pues se distinguen las piernas cruzadas en frente del mismo. La cabeza se encuentra agachada para poder absorber, simbólicamente, y por medio de un canuto adornado con plumones, la sangre producto del autosacrificio. Quizá los pequeños puntos observables debajo del canuto indiquen la sangre, como sucede en el hueso de Culhuacán, aunque en éste los puntos están dentro de corrientes simuladas por franjas con chalchihuites.

En el omichicahuaztli de Culhuacán puede notarse que el rostro del Sol se colocó originalmente boca abajo para absorber las corrientes de sangre originadas en los guerreros. También en el disco del Museum of the American Indian, la deidad lleva un objeto alargado en la boca

9 Ilustrado en Seler, 1902-23, vol. III, p. 399. 
que puede indicar, asimismo, la acción de chupar la sangre producto del sacrificio o del autosacrificio.

Un descubrimiento reciente en las excavaciones del Templo Mayor se relaciona con la idea de la absorción, por parte de los dioses, de la sangre producto del autosacrificio. Se trata de un punzón de hueso de $15 \mathrm{~cm}$ de largo hallado en la ofrenda de la caja número 29 (lámina 5). Como dicho punzón no presenta muescas no es un instrumento musical, sino debe haberse usado para el autosacrificio. El diseño inciso en dicho hueso, con plumas y plumones sobre el eje y a sus lados, puede indicar que se trataba de representar un canuto y, por lo tanto, que el instrumento empleado para mortificarse se convertía simbólicamente en el vehículo para la absorción del líquido sagrado. En el quauhxicalli, con corazones en su borde superior, labrado en la alfarda izquierda del Teocalli de la Guerra Sagrada se figuró asimismo el canuto con plumas y plumones para succionar la sangre 10 (lámina 6). Sahagún, al referirse a las ceremonias posteriores al sacrificio, cuando la sangre estaba en un recipiente, nos dice: "en la misma jicara iba un cañuto también aforrado con plumas; iba luego a andar las estaciones visitando todas las estatuas de los dioses ...: a cada uno de ellos ponía el cañuto teñido con la sangre, como dándole a gustar la sangre de su cautivo." 11

Como dejé anotado anteriormente, en varias páginas del Códice Borgia se dibujó cómo se alimentan los dioses con la sangre humana. En la página 41 de dicho códice, dos personajes ataviados como dioses se mutilan los genitales con punzones de huesos; la corriente de sangre originada en las heridas llega a las bocas de Tonacatecuhtli y Tonacacíhuatl, los dos dioses primigenios. ${ }^{12}$ En la página 50, la sangre de dos figuras humanas decapitadas se dirige hacia la banda que sirve de cobertor a dos dioses, representación que simboliza probablemente el acto sexual, lo que indica la relación de la sangre con la fertilidad. Esta misma idea de la sangre fertilizante aparece en la página 53 del Códice Borgia, en la cual Macuilxóchitl y Quetzalcóatl se perforan, con punzones de hueso, los genitales, y la sangre riega la tierra de la que salen dos grandes mazorcas. La escena de la págiña 71 nos presenta a Tonatiuh, con un atavío espléndido, sentado sobre un trono y con un

10 Caso, 1927.

11 Sahagún, 1956, t, I, p. 146 .

12 La identificación de los dioses es de Nowotny, 1961. 
gran disco solar a su alrededor. Tonatiuh succiona la corriente de sangre emergente de una codorniz decapitada. La cabeza de la misma se colocó sobre el monstruo simbólico de la tierra, lo que indica la necesidad de alimentar tanto al sol como a la tierra misma (lámina 7). Una idea similar constituye la temática del hueso de Culhuacán, en donde, además del dios solar, la tierra recibe corrientes de sangre y hasta corazones que aprisiona en sus garras (lámina 2). Estas representaciones ilustran los textos de las fuentes que recogen las palabras dichas por los macehuales al ofrecer a sus hijos al Tepochcalli: "Por tanto os le damos por vuestro hijo, y le encargamos porque tenéis cargo de criar a los muchachos y mancebos, mostrándoles las costumbres, para que sean hombres valientes, y para que sirvan a los dioses Tlal. tecuhtli y Tonatiuh, que son la tierra y el sol."13 Otro texto repite la misma creencia; es un texto tomado del discurso que le decía la partera al niño cuando le cortaba el ombligo: "tu oficio y facultad es la guerra, tu oficio es dar a beber al sol con sangre de los enemigos, y dar a comer a la tierra, que se llama Tlaltecuhtli, con los cuerpos de tus enemigos."14

En las últimas dos páginas del Códice Borgia, se dibujaron ocho dioses, entre ellos a Tonatiuh, quienes reciben chorros de sangre de hombres que se perforan los lóbulos de las orejas, Este tipo de peniten. cia fue continuada por los tenochcas y constituye la temática principal de tres cajas pertenecientes a la cultura mexica: la caja del Museo de Hamburgo, la del Museum of the American Indian de Nueva York y la caja que lleva el nombre de Riva Palacio del Museo Nacional de Antropología.

Tonatiuh, rodeado del disco solar, está situado en el nivel celeste en ambos omichicahuaztlis; sin embargo, la representación de dicho nivel no es igual en ambos huesos, pues el del Metro muestra rasgos específicos de la iconografía del periodo de dominio mexica. La manera convencional de representar al nivel celeste en el arte mexica consiste de varios círculos dispuestos arriba de una banda horizontal con los llamados "ojos radiantes" y también con los "ojos colgantes" o "peciolados" como puede verse en la página 16 del Códice Borbónico. Los círculos y "ojos colgantes" parecen simbolizar a las estrellas; en cambio, los "ojos radiantes" han sido interpretados como Venus.

13 Sahagún, op. cit, $t$, $\mathbf{x}$ p. 299 .

14 Ibid, t. II, pp. 185 y 186 . 
En el hueso de Culhuacán hay un "ojo radiante" similar al tipo de "ojos radiantes" de los códices del Grupo Borgia y de los códices mixtecos; en cambio, en el fémur del Metro, el diseño es típicamente mexica. En las obras pertenecientes a la cultura mexica, los ojos radiantes se transforman, pues en lugar de ser un ojo del cual emergen elementos dispuestos radialmente, se convierten en rostros fantásticos con boca y ojos; además de que, por lo general, se alternan dos tipos: uno con contornos curvados hacia adentro y otro con los contornos curvados hacia afuera. La representación del omichicahuaztli del Metro es única hasta el momento pues presenta sólo un ojo radiante convertido en cara, mientras que el otro conserva un diseño más tradicional, a pesar de que el ojo central se sustituyó por una boca invertida. En este mismo motivo, parte de la superficie está reticulada, lo que también puede observarse en el "ojo radiante" del fémur de Culhuacán. El tipo de diseño empleado para el nivel celeste en este último aparece asimismo en otro hueso hallado en Cuitláhuac, el cual muestra la imagen de Ehécatl Quetzalcóatl. ${ }^{15}$ Es de interés agregar que los ojos radiantes convertidos en rostros son exclusivos de la escultura mexica, pues no aparecen en los códices de esta cultura ni tampoco en los que continuaron esa tradición, aun después de la Conquista.

Cabe preguntarse la razón por la que se sitúa al Sol en un cielo es. trellado con dos posibles signos del planeta Venus. Hay dos razones posibles: la primera implicaría que el cielo estrellado se consideraba como la representación generalizada del cielo, ya fuera diurno o nocturno; la otra sería que se trata del Sol en su travesía, en la noche, por el inframundo, fase en la que necesitaba alimentarse por medio de sacrificios y autosacrificios. En el fémur de Culhuacán, un extraño ser calavérico comparte, con las estrellas, el nivel celeste; podría ser quizá uno de los tzitzimime, seres destructivos asociados con el fin del Quinto Sol y de la humanidad.

La pieza analizada en este artículo presenta el interés adicional de tener grabada una fecha, colocada a la derecha entre la faja celeste y la cabeza de uno de los personajes. Como está dentro de un cuadrete es probable que se trate de un año y no de un día. ${ }^{16} \mathrm{La}$ fecha se compone del signo ácatl acompañado de nueve o diez numerales, ya que uno de ellos pudo desaparecer por las muescas talladas posterior.

15 Henning, 1913.

16 Nicholson, s.f., p. 3. 
mente a la escena. Las fechas representadas en las piezas mexicas habían sido interpretadas generalmente como fechas míticas, pero después de los estudios de Nicholson y de Umberger ${ }^{17}$ es necesario tomar en cuènta una posible interpretación histórica. La fecha 9 ácatl corresponde a los años de 1423 y 1475 dentro del periodo que nos interesa aquí, y la de 10 ácatl a 1411, 1463 y 1515. El estilo de la pieza, con diseños ya desarrollados por los mexicas, apunta a una fecha tardía para su elaboración: quizá el año de 1475, durante el gobierno de Axayácatl, o el de 1515 cuando reinaba Moztecuzoma Xocoyotzin.

La disposición de un personaje frente a otro, tal como se observa en el omichicahuaztli del Metro, es bastante común dentro del arte mexica; entre las obras, con la misma composición, pueden mencionarse la lápida de inauguración del Templo Mayor, el recipiente del lomo del quauhxicalli-océlotl y el Teocalli de la Guerra Sagrada. En los dos primeros, los personajes se autosacrifican al perforarse los lóbulos de las orejas, ritual practicado comúnmente en la sociedad mexica. Es probable que en la escena en el hueso del Metro se trate de la misma acción, aunque sólo en la figura de la derecha puede verse un objeto puntiagudo que traspasa la oreja y que debe ser parte del implemento usado en la mortificación. En algunas de las cajas mexicas que han llegado hasta nuestros días, como la del Museo de Hamburgo, la del Museum of the American Indian y la del Museo Nacional de Antro. pología, se observa claramente cómo los penitentes cogen las partes gruesas de fémures para horadarse las orejas. En relación al tipo de objeto utilizado es de interés la opinión de Doris Heyden: "los punzones de jaguar y de águila eran elementos rituales reservados para el tlatoani y para los principales", aunque, como la autora agrega posteriormente, "la ocasión en que se hacia el autosacrificio puede tam. bién haber determinado el material de los punzones". ${ }^{18}$

Es necesario preguntarse si las figuras grabadas en el hueso del Metro son dioses o personajes disfrazados a semejanza de ellos. La respuesta se dificulta por el hecho de que hay casos en que un tlatoani usa el atavío de una deidad, como sucede en la Piedra de Tízoc, en la que el soberano porta el yelmo de colibrí de Huitzilopochtli. También en el fémur del Metro, el personaje de la izquierda ostenta un tocado de colibri, cuyo pico alargado se prolonga hasta casi tocar al sujeto

17 Ibid. y Umberger, s.f.

18 Heyden, 1972, p. 30. 
frente a él. Junto al ojo de dicha ave se colocó una versión simplificada del espejo humeante consistente en un objeto circular con un gancho, un elemento bifurcado y una voluta. Esta versión simplifi. cada aparece asimismo en los códices Telleriano Remensis (láminas IX, XXV y XXXI) y Vaticano $A$ (láminas XLVII y LII), mientras que en el Códice Borbónico suele figurarse este símbolo en su forma más elaborada como puede verse en la página 17 de dicho códice; tanto una versión como la otra fueron talladas en las esculturas mexicas. El espejo humeante es característico de Tezcatlipoca en sus advocaciones diversas, así como también de Huitzilopochtli. Como la figura de la izquierda presenta el pico de un colibrí es probable que sea este último dios o un personaje ataviado como él.

El sujeto de la derecha es más difícil de identificar porque su tipo de tocado es de uso más generalizado. El tocado puede ser el aztaxelli o el cuauhpilolli; el color de las plumas, que es determinativo para saber de cuál se trata, no existe en el hueso del Metro. Entre los dioses que portan estos tocados podemos mencionar a Mixcóatl-Camaxtli, Tezcatlipoca e Itzpapálotl, pero lo usan asimismo hombres penitentes o que ofrecen sacrificios. Es importante hacer notar las semejanzas del personaje de este omichicahuaztli con el labrado en un lado de la hermosa caja del Museo de Hamburgo. El tipo de tocado, el fleco sobre la frente y el círculo pequeño a un lado de la nariz son los mismos en ambos casos. Por los estudios hechos por Umberger sobre dicha caja ${ }^{19}$ es probable que la figura sea la de Moctecuzoma Xocoyotzin, pues aparece su glifo onomástico junto a él. En el caso de la pieza del Metro, si la fecha grabada corresponde a 1515, pudiera tratarse del mismo gobernante.

No se debe descartar, sin embargo, la posibilidad de que sean deidades las representadas, pues en el lomo del quauhxicalli-océlotl aparecen dos dioses, ataviados en forma similar, en el acto de perforarse las orejas. Estos dioses fueron identificados por Beyer como Huitzilo. pochtli (el de la izquierda) y Tezcatlipoca (el de la derecha). ${ }^{20}$ Espejos humeantes esquematizados emergen de las sienes de ambos.

Al extremo derecho del fémur del Metro se grabó una cabeza humana independiente de la escena principal, la cual muestra un tocado con dos cuchillos, y lleva en el rostro una especie de antifaz con circu.

19 Umberger, op. cit.

20 Beyer, 1965, p. 374. 
los pequeños. Los pedernales del tocado inducen a pensar que puede tratarse de Tezcatlipoca, pues en el Códice Matritense del Real Palacio se les menciona como componentes del tocado de dicho dios ${ }^{21}$ pero, en cambio, el antifaz lo hallamos en el Códice Borbónico en los rostros de Tlahuizcalpantecuhtli, Atlahua y Huitzilopochtli, y en el Códice Matritense en las caras de Painal y Atlahua; Ia falta de mayores datos impiden determinar la identidad de la cara figurada.

En resumen, la ideologia desarrollada durante el Posclásico y que culmina en el periodo de dominio mexica, está reflejada claramente tanto en el omichicahuaztli del Metro como en el de Culhuacán. La necesidad de alimentar con sangre humana al dios solar, preocupación primordial dentro de la cultura mexica, ya sea con el sacrificio de cautivos o por medio del autosacrificio, es la creencia grabada en dichos objetos. La importancia del autosacrificio, acto representado en obras tan primordiales como la lápida que conmemora la inauguración del Templo Mayor, el relieve conocido como Acuecuéxcatl y el del lomo del quauhxicalli-océlotl radicaba en que no sólo complementaba a los sacrificios, además era una ceremonia practicada por todo el pueblo, y era a través de ritos comunales como se lograba, en parte, la cohesión de la sociedad mexica.

21 Ritos, sacerdotes y atavios, 1958, p. 117. 

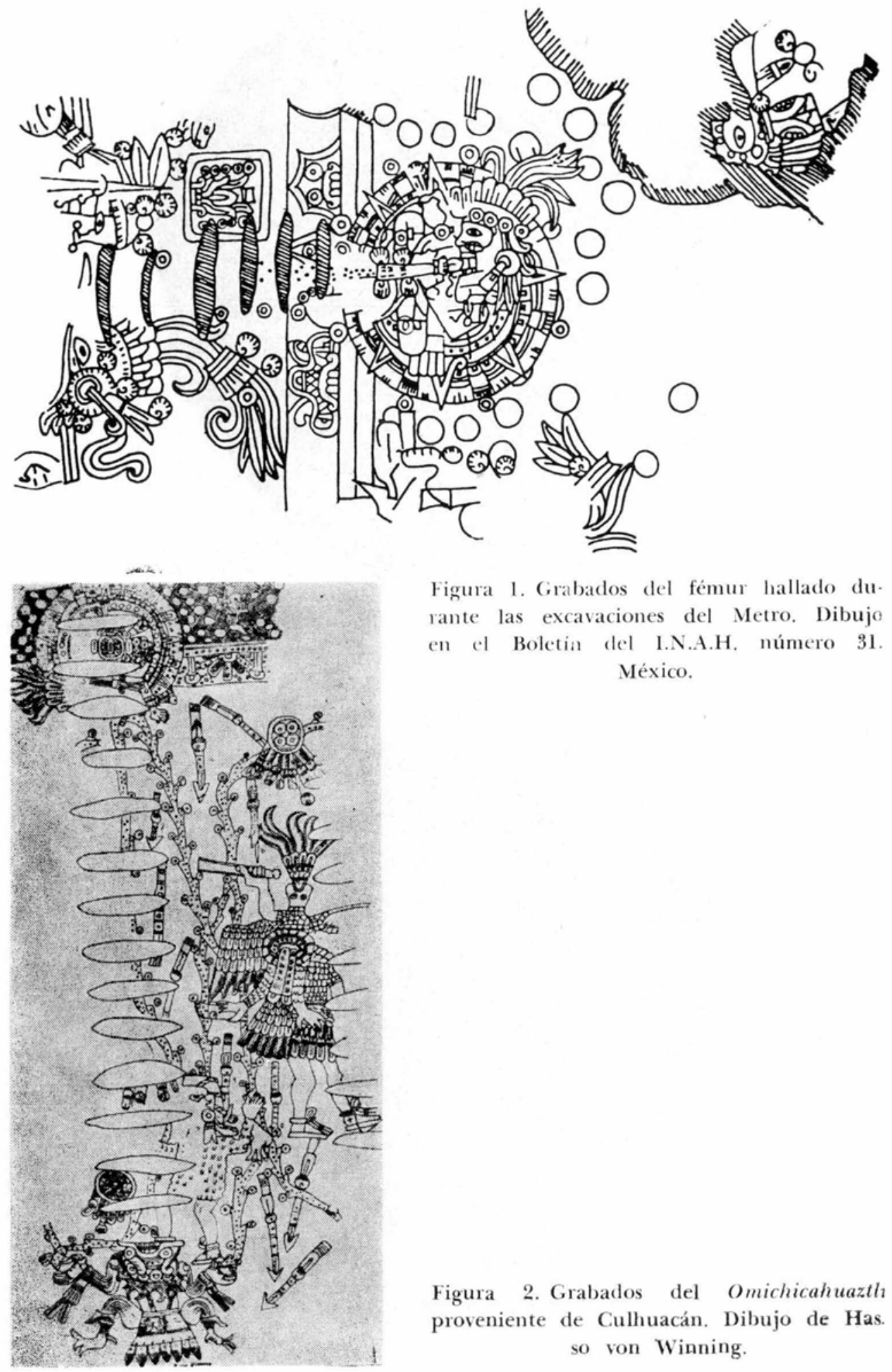

Figura 1. Grabados del fémur hallado du. rante las excavaciones del Metro. Dibujo en el Boletin del I.N.A.H. número 31. México.

Figura 2. Grabados del Omichicahuazth proveniente de Culhuacán. Dibujo de Has. so von Winning. 


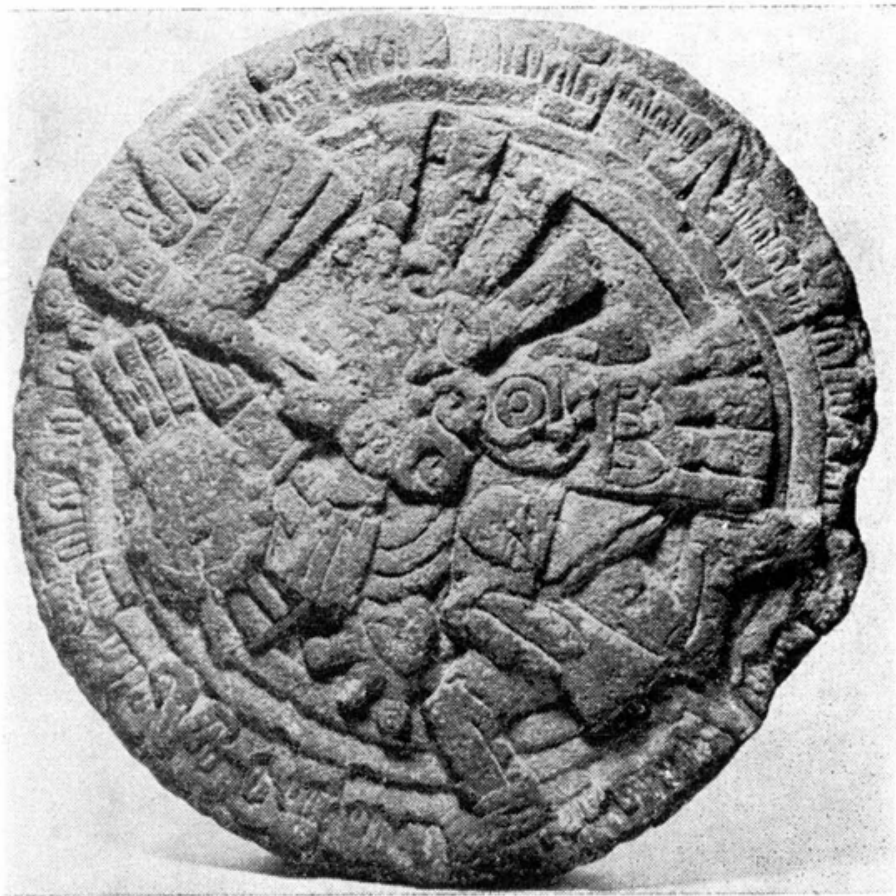

Figura 3. Disco con la deidad solar. Fotografía cortesia del Museum of the American Indian, Heye Foundation.

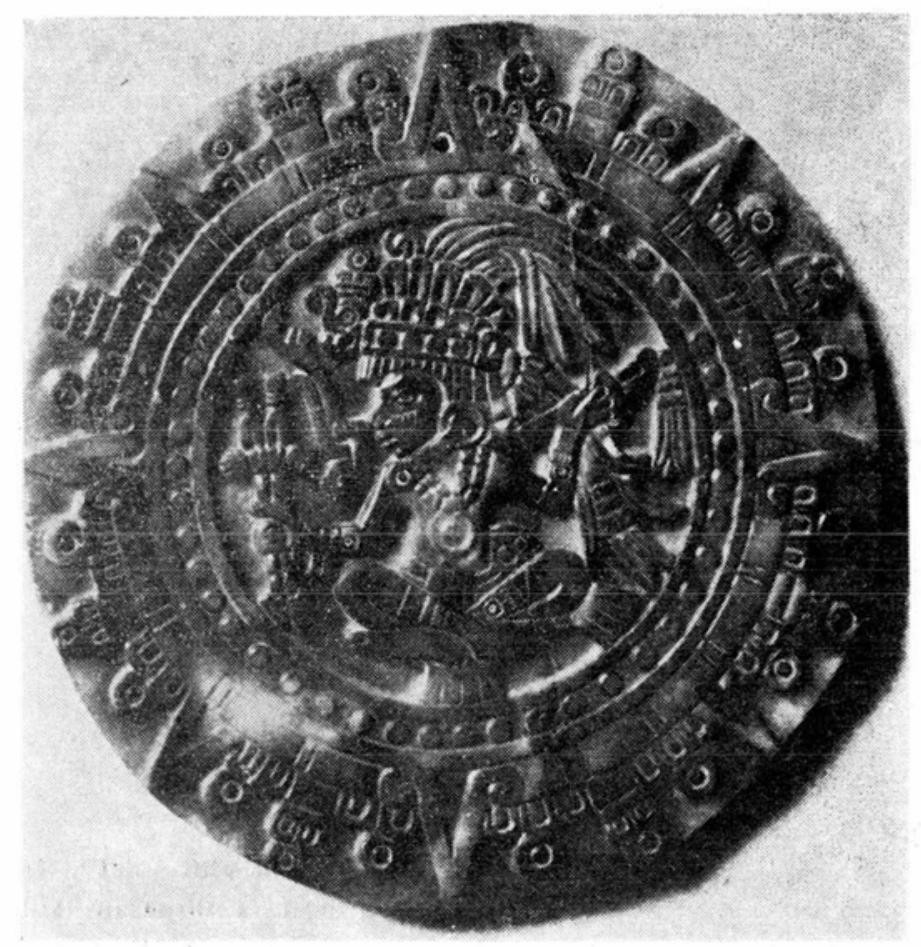

Figura 4. Pieza conocida con el nombre de Disco Humboldt. 


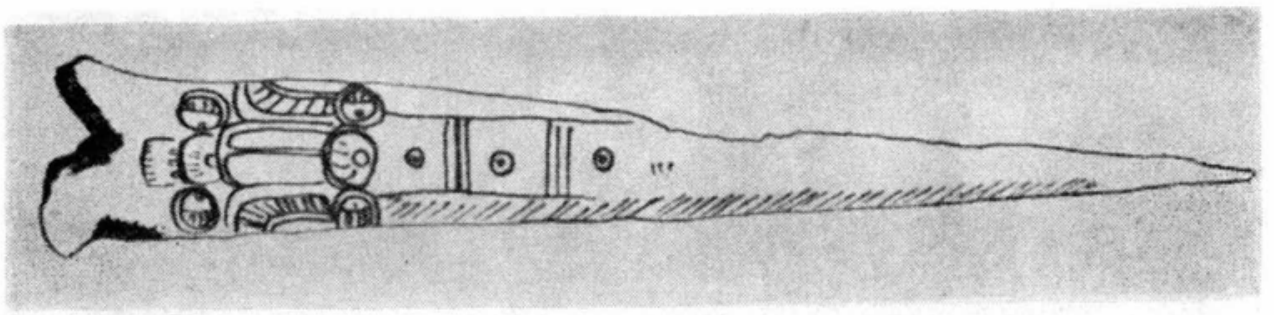

Figura 5. Dibujo de un punzón de hueso encontrado en las excavaciones del Templo Mayor. Dibujo de Francisco Hinojosa.

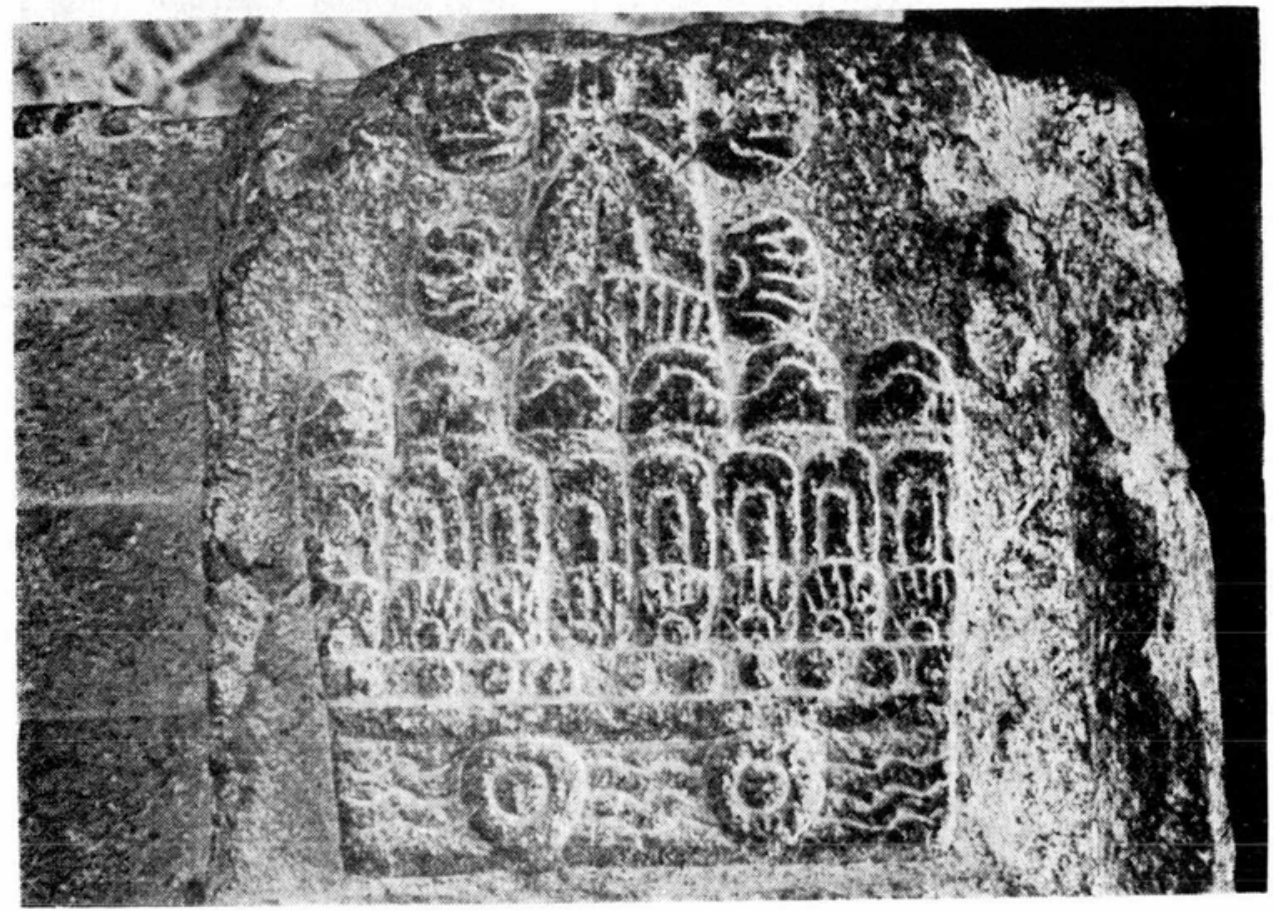

Figura 6. Quauhxicalli labrado en la alfarda izquierda del Teocalli de la Guerra Sagrada. Fotografía de Pedro Cuevas. 


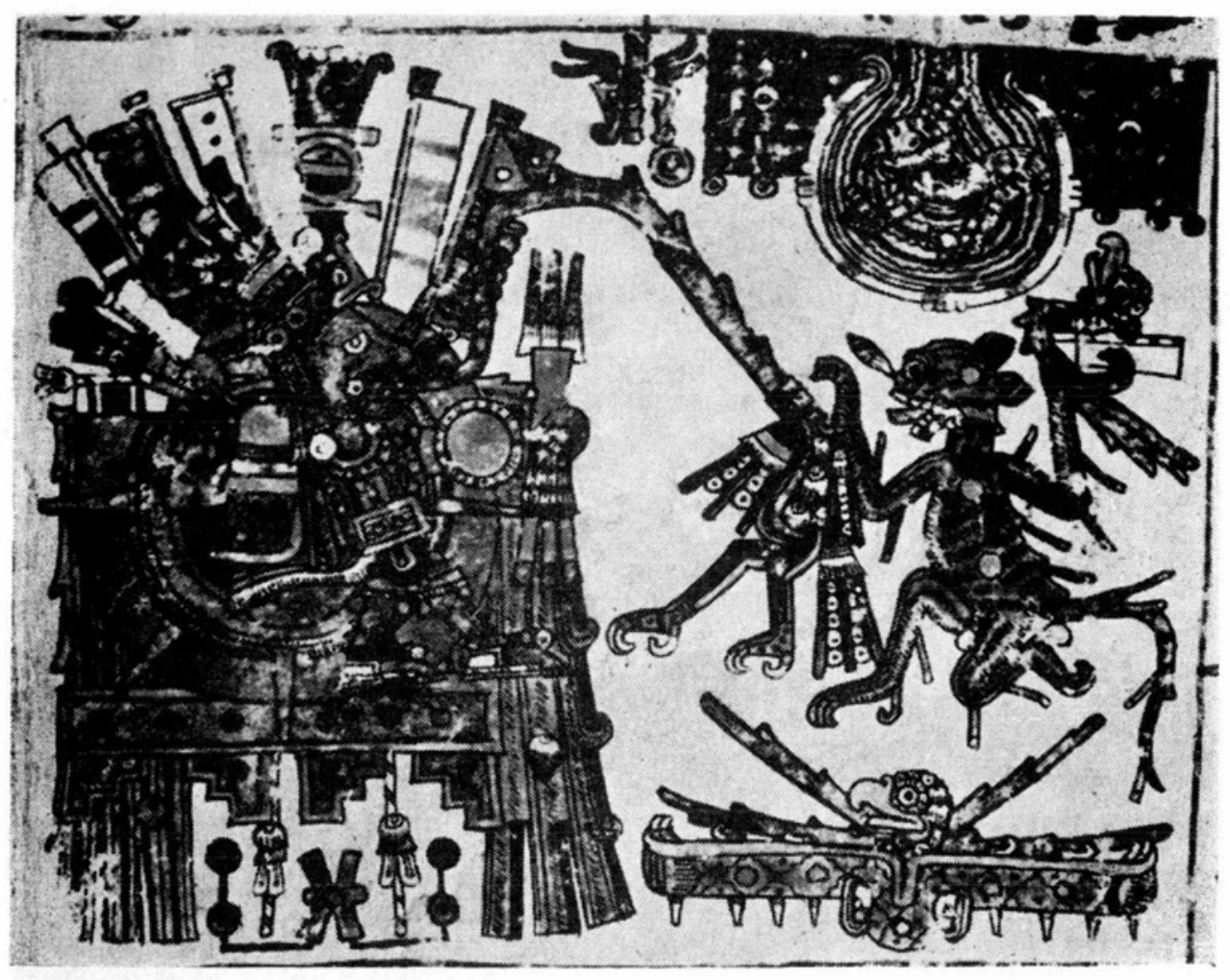

Figura 7. Sacrificio de un ave al dios solar y al monstruo terrestre. Códice Borgia, página 71 . 


\section{BIBLIOGRAFIA}

Aivarado Tezozómoc $\mathrm{H}$.

1943 Crónica Mexicana. México, UNAM, Biblioteca del Estudiante Universitario, núm. 41.

BEYER, $\mathrm{H}$

1965 "Mito y simbología del México antiguo". El México Antiguo, Mé xico, tomo $x$

1969 "Un instrumento musical de los antiguos mexicanos". El México Antiguo, México, tomo xı, pp. 536-540.

Caso, A.

1927 El Teocalli de la Guerra Sagrada. México.

1967 Los Calendarios Prehispánicos. México, UNAM.

Cepeda G. y R Martín Arana.

1968 "Hueso grabado del centro de México". Boletin del INAH, México. INAH, núm. 31, pp. 38-41.

CODEX Borbonicus

1974 "Codex Borbonicus". Codices Selecti, vol. xurv, Akademische Druck-u. Verlagsanstalt, Graz, Austria.

CODEX Cospi

1968 "Codex Cospi". Codices Selecti, vol, xviII, Akademische Druck-u. Verlagsanstalt, Graz, Austria.

CODEX FejérVÁRI-MAYER

1971 "Codex Fejérváry-Mayer". Codices Selecti, vol. xxiI, Akademische Druck-u. Verlagsanstalt, Graz, Austria.

Codex Magl iabecchiano

1970 "Codex Magliabecchiano". Codices Selecti, vol. XxIII, Akademische Druck-u. Verlagsanstalt, Graz, Austria.

Codex Vaticanus 3773

1972 "Codex Vaticanus 3773". Codices Selecti, vol. $\mathrm{xx \times ̄vī,} \mathrm{Akademische}$ Druck-u. Verlagsansatalt, Graz, Austria.

\section{Códice Laud}

1964 "Códice Laud". Antigüedades de México basadas en la recopilación de Lord Kingsborough, vol. 3, México.

\section{Códice Telleriano Remensis}

1964 "Códice Telleriano Remensis". Antigüedades de México basadas en la recopilación de Lord Kingsborough, vol 1, México.

Códice Vairgano A

1964 "Códice Vaticano A". Antigüedades de México basadas en la recopilación de Lord Kingsborough, vol. 3, México.

DIETSCHY, $\mathrm{H}$.

1941 "Zwei altmexikanische Steinbilder von Sonnengöttern". Ethnos, Estocolmo, núms. 1-2. 
GutírRez Solana, N.

s.f. Objetos ceremoniales pertenecientes a la cultura mexica; su estudio artístico. Tesis doctoral, México, UNAM.

Henning, $\mathbf{P}$.

1913 "El fémur esgrafiado de Tlahuac". Anales del Museo Nacional de Arqueologia, Historia y Etnografía, época 3a., tomo 5, nưm. 4, pp. 263-278.

HEYDEN, D.

1972 "Autosacrificios prehispánicos con púas y punzones". Boletin del INAH, México, época II, núm. 1, pp. 27-30.

Nicholson, H. B.

s.f. Aztec Style Calendric Inscriptions of Possible Historial Significance: A Survey (mimeografiado).

1975 "The Late Pre-Hispanic Central Mexican (Aztec) Iconographic System". Iconography of Middle America, New York, The Metropolitan Museum of Art, pp. 72-97.

Nowotny, K. A.

1961 "Tlacuilolli: die mexikanischen Bilderhandschriften, Stil und Inhalt." Ibero-Amerikanischen Bibliothek, Monumenta Americana 3, Berlin.

Ritos, sacerdotes y atavios de los dioses

1958 "Ritos, sacerdotes y atavíos de los dioses". Ed. de M. León Portilla. Textos de los informantes de Sahagún, México, UNAM, núm. 1.

SAHAGún, B. de

1956 Historia general de las cosas de la Nueva España. México, Fd. Porrúa.

SELER, E.

1902- Gessammelte Abhandlungen zur Amerikanischen Sprach-und Alter-

23 tumskunde. Graz, Austria.

1963 Comentarios al Códice Borgia. México, F C...

SPRANZ, B.

1973 Los dioses en los códices mexicanos del Grupo Borgia. México, F.C.E.

TOWNSEND, R. F.

1979 "State and Cosmos in the Art of Tenochtitlan". Studies in Pre-Columbian Art and Archaeology, Washington, Dumbarton Oaks., número 20.

WINNING, H. voN

1959 "A decorated bone rattle from Culhuacan, Mexico". American An tiquity, Salt Lake City, tomo 25, núm.. 1, pp. 86-93.

UMBERGER, E.

s.f. Aztec Sculptures, Hieroglyphs and History. Tesis doctoral, Columbia University. 